\title{
Are the common genetic variants associated with colorectal cancer risk for DNA mismatch repair gene mutation carriers?
}

\author{
Aung Ko Win ${ }^{1}$, John L. Hopper ${ }^{1}$, Daniel D. Buchanan², Joanne P. Young ${ }^{2}$, Albert Tenesa ${ }^{3,4}$, \\ James G. Dowty ${ }^{1}$, Graham G. Giles ${ }^{5}$, Jack Goldblatt ${ }^{6}$, Ingrid Winship ${ }^{7,8}$, Alex \\ Boussioutas $^{9,10,11}$, Graeme P. Young ${ }^{12}$, Susan Parry ${ }^{13,14}$, John A. Baron ${ }^{15}$, David \\ Duggan $^{16}$, Steven Gallinger ${ }^{17,18}$, Polly A. Newcomb ${ }^{19}$, Robert W. Haile ${ }^{20}$, Loïc Le \\ Marchand $^{21}$, Noralane M. Lindor ${ }^{22}$, and Mark A. Jenkins ${ }^{1}$
}

${ }^{1}$ Centre for Molecular, Environmental, Genetic and Analytic Epidemiology, The University of Melbourne, Parkville, Victoria, Australia ${ }^{2}$ Cancer and Population Studies Group, Queensland Institute of Medical Research, Bancroft Centre, Herston, Queensland, Australia ${ }^{3}$ The Roslin Institute, University of Edinburgh, Edinburgh, Scotland ${ }^{4}$ Medical Research Council Human Genetics Unit, Institute of Genetics and Molecular Medicine, University of Edinburgh, Western General Hospital, Edinburgh, Scotland ${ }^{5}$ Cancer Epidemiology Centre, Cancer Council Victoria, Carlton, Victoria, Australia ${ }^{6}$ Genetic Services of Western Australia and School of Paediatrics and Child Health, University of Western Australia, Perth, Australia ${ }^{7}$ Department of Medicine, The University of Melbourne, Parkville, Victoria, Australia ${ }^{8}$ Genetic Medicine, The Royal Melbourne Hospital, Parkville, Victoria, Australia ${ }^{9}$ Department of Medicine, Royal Melbourne Hospital, The University of Melbourne, Parkville, Australia ${ }^{10} \mathrm{Cancer}$ Genomics and Predictive Medicine, Peter MacCallum Cancer Centre, East Melbourne, Victoria, Australia ${ }^{11}$ Sir Peter MacCallum Department of Oncology, The University of Melbourne, Parkville, Victoria, Australia ${ }^{12}$ Flinders Centre for Innovation in Cancer, Flinders University, Adelaide, South Australia, Australia ${ }^{13} \mathrm{New}$ Zealand Familial Gastrointestinal Cancer Registry, Auckland City Hospital, Auckland, New Zealand ${ }^{14}$ Department of Gastroenterology, Middlemore Hospital, Auckland, New Zealand New Zealand ${ }^{15}$ Department of Medicine, University of North Carolina, Chapel Hill, North Carolina, USA ${ }^{16}$ Genetic Basis of Human Disease Division, Translational Genomics Research Institute (TGen), Phoenix, Arizona, USA ${ }^{17}$ Samuel Lunenfeld Research Institute, Mount Sinai Hospital, Toronto, Ontario, Canada ${ }^{18} \mathrm{Cancer}$ Care Ontario, Toronto, Ontario, Canada ${ }^{19} \mathrm{Cancer}$ Prevention Program, Fred Hutchinson Cancer Research Center, Seattle, Washington, USA ${ }^{20}$ Department of Preventive Medicine, University of Southern California, Los Angeles, California, USA ${ }^{21}$ University of Hawaii Cancer Center, Honolulu, Hawaii, USA ${ }^{22}$ Department of Health Science Research, Mayo Clinic Arizona, Scottsdale, Arizona, USA

\footnotetext{
() 2013 Elsevier Ltd. All rights reserved.

Corresponding author: Mark A. Jenkins, $\mathrm{PhD}$, Centre for Molecular, Environmental, Genetic and Analytic Epidemiology, Melbourne School of Population Health, Level 3, 207 Bouverie Street, The University of Melbourne VIC 3010, Australia, Tel: +61 3 8344 0902, Fax: +61 39349 5815, m.jenkins@ unimelb.edu.au.

Publisher's Disclaimer: This is a PDF file of an unedited manuscript that has been accepted for publication. As a service to our customers we are providing this early version of the manuscript. The manuscript will undergo copyediting, typesetting, and review of the resulting proof before it is published in its final citable form. Please note that during the production process errors may be discovered which could affect the content, and all legal disclaimers that apply to the journal pertain.

Disclaimer

The content of this manuscript does not necessarily reflect the views or policies of the National Cancer Institute or any of the collaborating centers in the CFRs, nor does mention of trade names, commercial products, or organizations imply endorsement by the US Government or the CFR. Authors had full responsibility for the design of the study, the collection of the data, the analysis and interpretation of the data, the decision to submit the manuscript for publication, and the writing of the manuscript.

Conflict of interest statement

The authors have no conflict of interest to declare with respect to this manuscript.
} 


\section{Abstract}

Background-Genome-wide association studies have identified at least 15 independent common genetic variants associated with colorectal cancer (CRC) risk. The aim of this study was to investigate whether 11 of these variants are associated with CRC risk for carriers of germline mutations in DNA mismatch repair (MMR) genes.

Methods-A total of 927 MMR gene mutation carriers (360 MLH1, 442 MSH2, 85 MSH6 and 40 PMS2) from 315 families enrolled in the Colon Cancer Family Registry, were genotyped for the SNPs: rs16892766 (8q23.3), rs6983267 (8q24.21), rs719725 (9p24), rs10795668 (10p14), rs3802842 (11q23.1), rs4444235 (14q22.2), rs4779584 (15q13.3), rs9929218 (16q22.1), rs4939827 (18q21.1), rs10411210 (19q13.1) and rs961253 (20p12.3). We used a weighted Cox regression to estimate CRC risk for homozygous and heterozygous carriers of the risk allele compared with homozygous non-carriers as well as for an additive per allele model (on the log scale).

Results-Over a total of 40,978 person-years observation, 426 (46\%) carriers were diagnosed with CRC at a mean age of 44.3 years. For all carriers combined, we found no evidence of an association between CRC risk and the total number of risk alleles (hazard ratio [HR] per risk allele $=0.97,95 \%$ confidence interval $[\mathrm{CI}]=0.88-1.07, \mathrm{p}=0.52$ ).

Conclusions-We found no evidence that the SNPs associated with CRC in the general population are modifiers of the risk for MMR gene mutation carriers overall, and therefore any evidence of proven clinical utility in Lynch syndrome.

\section{Keywords}

genetic variant; colorectal cancer; Lynch syndrome; mismatch repair

\section{INTRODUCTION}

Colorectal cancer (CRC) is one of the most frequently diagnosed cancers worldwide, with over one million diagnosed cases (9.8\% of cancer diagnoses) and $~ 600,000$ deaths ( $8.1 \%$ of all cancer deaths) in 2008(1). Approximately 3-4\% of all CRC(2), and 5-15\% of CRC diagnosed before age 50 years $(3,4)$, are Lynch syndrome cases caused by germline mutations in a DNA mismatch repair (MMR) gene; MLH1, MSH2, MSH6 and PMS2(5). Average cumulative risk of CRC to age 70 years for MMR gene mutation carriers has been varyingly estimated between $20 \%$ and $70 \%$ depending on sex and the MMR gene that is mutated(6-8). Cancer risks for $M L H 1$ and $M S H 2$ mutation carriers vary greatly from family to family(9), consistent with the existence of multiple inherited genetic (polygenic) modifiers.

Several genome-wide association studies (GWAS) have identified single nucleotide polymorphisms (SNPs) in at least 15 independent loci associated with CRC risk (odds ratio ranging from 1.10 to 1.26 per risk allele)(10-12) (Supplementary Table 1). If these SNPs also predicted CRC risk in MMR gene mutation carriers, there would be a potential to use them to more accurately predict individual risk estimates for Lynch syndrome. Three studies observed two variants, 8q23.3 (rs16892766) and 11q23.1 (rs3802842), to be associated with increased risk of CRC in Lynch syndrome especially for females only $(13,14)$ or $M L H 1$ mutation carriers only $(14,15)$; however, another study(16) observe no associations. In this study of MMR gene mutation carriers, we have investigated associations of CRC with SNPs at 11 loci: 8q23.3 (rs16892766), 8q24.21 (rs6983267), 9p24 (rs719725), 10p14 (rs10795668), 11q23.1 (rs3802842), 14q22.2 (rs4444235), 15q13.3 (rs4779584), 16q22.1 (rs9929218), 18q21.1 (rs4939827), 19q13.1 (rs10411210) and 20p12.3 (rs961253). 


\section{MATERIALS AND METHODS}

\section{Study Sample}

Subjects were heterozygote carriers of pathogenic mutations in MMR genes who were recruited from the Colon Cancer Family Registry (Colon CFR). Details of recruitment, data collection and mutation testing have been described in detail previously $(17,18)$. Written informed consent was obtained from all subjects, and the study protocol was approved by the institutional human ethics committee at each center of the Colon CFR.

\section{Genotyping of the SNPs}

Genotyping for SNPs was performed using Sequenom's iPLEX Gold. PCR and extension primers for these SNPs were designed using the MassARRAY Assay Design 3.0 software (Sequenom, Inc.). Extension product sizes were determined by mass spectrometry using Sequenom's Compact matrix-assisted laser desorption ionization-time of flight mass spectrometer. Resulting mass spectra were converted to genotype data using SpectroTYPER-RT software. Genotype data from 30 CEPH trios (Coriell Cell Repository, Camden, NJ) were used to confirm reliability and reproducibility of the genotyping. No errors of Mendelian inheritance were detected in the CEPH trios and genotypes for these subjects showed perfect concordance with genotypes from the International HapMap Project.

\section{Statistical Analysis}

Cox proportional hazards regression analysis was used to estimate hazard ratios (HRs) and 95\% confidence intervals (CIs) for the published CRC risk allele of each SNP to CRC risk for MMR gene mutation carriers. We estimated HRs separately for homozygous carriers of the risk allele ( 2 risk alleles) and heterozygous carriers of the risk allele (1 risk allele) versus homozygous carriers of the non-risk allele ( 0 risk allele); and we estimated HRs per risk allele, i.e. a linear association on the log scale. We also estimated the association with the total number of risk alleles over the SNPs, i.e. 0-22. (see Supplementary Table 1 for risk alleles).

Since some carriers were ascertained because they were diagnosed with CRC, the identification of MMR gene mutation carriers was not random with respect to CRC. To adjust for this non-random ascertainment, we used the weighted cohort approach(19). Previously estimated age-specific CRC incidence rates for MMR gene mutation carriers(20) were used to calculate sampling fractions to weight the proportion of CRC-affected and unaffected carriers in 5-year age stratum so the proportion of affected carriers in each age group equalled that expected for mutation carriers in the population.

Time-at-risk started at birth and ended at age at diagnosis of CRC $(\mathrm{n}=426)$, any other cancer $(n=92)$, polypectomy $(n=132)$, death $(n=4)$ or last contact $(n=273)$, whichever occurred first. Proportional hazards assumption was tested by examining the relationship between the scaled Schoenfeld residuals and survival time (21). Associations between genetic variants and CRC risk were estimated stratified by gender and the MMR gene that was mutated after adjusting for country of recruitment and ascertainment source (clinic- or population-based). To allow for any correlation of risk between family members, the HuberWhite robust variance correction was applied by clustering on family membership (22).

To reduce false discovery rate expected from the large number of associations investigated, the p-value cut-off for classifying a HR as statistically significant was determined using methods by Benjamini and Hochberg (23). This method controls the expected high false 
discovery rate and can result in power gains over traditional multiplicity 'correction' methods such as the Bonferroni procedure(24).

A test of the null hypothesis (no association between any of the genetic variants and CRC risk) against the alternative hypothesis (associations with CRC risk in the same direction as in the general population) was conducted using Fisher's test of whether the distribution of one-sided p-values from fitting the additive per allele association on the log scale deviated from the uniform distribution on the interval $[0,1]$. This was done by summing the $-2 \ln \mathrm{p}_{\mathrm{i}}$, where $\mathrm{p}_{\mathrm{i}}$ is the $\mathrm{p}$-value for the th variant, across all SNPs and comparing with the $\chi^{2}$ distribution with $2 n$ degrees of freedom, where $n$ is the number of SNPs(25). Statistical analyses were performed using Stata 11.0(26).

\section{RESULTS}

A total of 927 MMR gene mutation carriers from 315 families (117 MLH1, 136 MSH2, 41 MSH6, and 21 PMS2) were included in this study. Over 40,978 person-years observation, $426(46 \%)$ carriers were diagnosed with CRC at a mean age of 44.3 (standard deviation, SD 11; median 44, range 17-80) years. Of all carriers, 738 (223 families) were recruited in Australia or New Zealand, 164 ( 77 families) in the USA and 25 (15 families) in Canada (Table 1). SNP genotype frequencies did not deviate from that expected under HardyWeinberg equilibrium except for $\mathrm{rs} 3802842(\mathrm{p}=0.004)$ and $\mathrm{rs} 6983267(\mathrm{p}=0.002)$ (Table 2).

We found no evidence of an increased CRC risk associated with any of the 11 SNPs overall or separately for male and female carriers (Figure 1 and 2). Also, there was no evidence of an association between the total number of risk alleles of the 11 SNPs (as a continuous factor) and $\mathrm{CRC}$ risk (HR per risk allele $=0.97,95 \% \mathrm{CI}=0.88-1.07, \mathrm{p}=0.52$ all carriers combined; $\mathrm{HR}=0.99,95 \% \mathrm{CI}=0.86-1.14, \mathrm{p}=0.87$ for males; $\mathrm{HR}=0.96,95 \% \mathrm{CI}=0.84-1.10$, $\mathrm{p}=0.56$ for females; $\mathrm{HR}=0.98,95 \% \mathrm{CI}=0.82-1.18, \mathrm{p}=0.86$ for $M L H 1 ; \mathrm{HR}=0.95$, $95 \% \mathrm{CI}=0.82-1.10, \mathrm{p}=0.50$ for $M S H 2, \mathrm{HR}=1.03,95 \% \mathrm{CI}=0.85-1.26, \mathrm{p}=0.74$ for $M S H 6$; $\mathrm{HR}=0.82,95 \% \mathrm{CI}=0.50-1.32, \mathrm{p}=0.41$ for $P M S 2$ ). We also found no evidence of variation from a uniform distribution of CRC risk for the SNPs ( $\mathrm{p}=0.53$ for all carriers combined, 0.83 for males, 0.72 for females, 0.80 for $M L H 1,0.61$ for $M S H 2,0.0005$ for $M S H 6$ and 0.39 for PMS2).

For PMS2 mutation carriers, carriers of the G-allele of rs 10795668 (10p14) were at decreased risk of $\mathrm{CRC}(\mathrm{HR}=0.07,95 \% \mathrm{CI}=0.01-0.40, \mathrm{p}=0.003$ for $\mathrm{AG}$ carriers; and $\mathrm{HR}=0.03,95 \% \mathrm{CI}=0.00-0.39, \mathrm{p}=0.007$ for $\mathrm{GG}$ carriers compared with AA carriers). For PMS2 mutation carriers, carriers of the G-allele of rs992918 (16q22.1) were also at decreased risk of $\mathrm{CRC}(\mathrm{HR}=0.14,95 \% \mathrm{CI}=0.03-0.61, \mathrm{p}=0.009$ for $\mathrm{GA}$ carriers; and $\mathrm{HR}=0.07,95 \% \mathrm{CI}=0.01-0.51, \mathrm{p}=0.008$ for $\mathrm{GG}$ carriers compared with AA carriers). For MSH2 mutation carriers, homozygous carriers of the $\mathrm{C}$ allele of rs 16892766 were at increased risk of CRC compared with homozygous carriers of the A allele (HR=10.74, 95\% CI=2.24-51.39, $\mathrm{p}=0.003$ ) (Table 3).

\section{DISCUSSION}

Our analyses provided no evidence to support the hypothesis that, overall, the SNPs associated with CRC risk for the general population are also associated with CRC risk for MMR gene mutation carriers, let alone having associations in the same direction. We found no evidence for SNP associations with CRC for all carriers combined, or when stratified by gender. Our estimate of $\mathrm{CRC}$ risk per allele for mutation carriers $(\mathrm{HR}=0.97,95 \% \mathrm{CI}=0.88$ 1.07) was lower $(\mathrm{p}=0.03)$ than reported for the general population $(\mathrm{OR}=1.09,95 \% \mathrm{CI}=1.05-$ 1.13) (27). 
These findings strongly suggest that the GWAS SNPs for CRC in the general population are not useful predictors for CRC in those with an inherited MMR gene mutation. Whatever the reason for the association between these SNPs and CRC, whether it be due to linkage disequilibrium with a common or rare causal genetic variant, protein binding site or promoter region, they do not appear to be having the same effect in carriers of high-risk mutations. Perhaps cancers with microsatellite instability, i.e. Lynch syndrome cancers, are not subject to the same slight effects that these SNPs have on the more common microsatellite stable cancers. Is this apparent lack of SNP and cancer association carriers of MMR gene mutations also seen for carriers of other high-risk cancer genes? Two of the six GWAS SNPs associated with breast cancer in the general population were also associated with breast cancer risk for carriers of $B R C A 1$ mutations, and five of the six SNPs were associated with breast cancer risk for $B R C A 2$ mutation carriers(28). It appears then, that the predictive utility of SNPs identified by GWAS using cancer in the general population, for predicting cancer in carriers of high-risk mutations, may depend on the specific high-risk gene; no utility for MMR genes; almost no utility for BRCA1, and some utility for BRCA2.

Further, as shown in Figure 1, for all carriers combined, only 3 of SNPs had a point estimate greater than one for the OR per allele for association with CRC. If these associations for MMR gene mutation carriers were consistent with studies for the general population, we would expect all of the SNPs to be positively associated with risk, i.e. OR $>1$. The apparent difference in estimates for SNP associations with CRC between MMR gene mutation carriers and the general population might be due to differences in the pathogenesis of these cancers, as exemplified by differences in tumor location in the large intestine. Proximal and distal colon have been different gene expression profiles and risk factors(29-31). Lynch syndrome-associated CRCs are more likely to present in the proximal colon compared with CRCs in the general population. In addition, differential effects for SNPs may also arise due to the differing mechanisms of carcinogenesis: Lynch syndrome, specifically progression via microsatellite instability, in contrast with the chromosomal instability which characterises population-based CRC.

This is the only study assessing the CRC SNPs for PMS2 mutation carriers. We observed heterozygous and homozygous carriers of the $\mathrm{G}$ alleles for the rs 10795668 and rs 9929218 SNPs were at decreased CRC risk, i.e. the opposite direction to that observed for the general population. Although our study group consisted of only 40 PMS 2 mutation carriers, the observed associations were significant after correction for multiple testing-suggesting these findings are not spurious. However, further validation in larger sample set of PMS 2 mutation carriers is necessary. There was evidence suggesting that rs 10795668 varied by tumor site, being more common in rectal than colonic tumors(32). In contrast, Lynch syndrome associated CRCs occur predominantly in the proximal colon and therefore, the findings from this study for rs 10795668 in PMS2 mutation carriers may reflect an indirect association related to tumor location.

The association between homozygous carriers of the $\mathrm{C}$ allele of rs 16892766 and CRC risk for $\mathrm{MSH} 2$ mutation carriers was in the same direction as reported for CRC from the general population(32). In the general population, the association was stronger for CRC diagnosed under age 60 years suggesting potential age modifying effects in MMR gene mutation carriers. This SNP has also been reported as a CRC risk modifier for MMR gene mutation carriers in three other studies(13-15); but not in one study(16). Talseth-Palmer et al.(14) did not observe a significant effect of rs 16892766 alone on CRC risk but observed a trend of an increased risk of CRC for the pair-wise combination of SNPs rs3802842 and rs16892766 in MLH1 mutation carriers. In contrast, Houlle et al.(16) reported a decreased risk of CRC $(\mathrm{HR}=0.27,95 \% \mathrm{CI}=0.08-0.86, \mathrm{p}=0.03)$ for homozygous carriers of the $\mathrm{C}$ allele in mutation carriers overall. The lack of consistency in the results between our study and this study(16) 
could be attributable to the small number of homozygous carriers of the $\mathrm{C}$ allele of rs 16892766 identified in each study. We concluded a meta-analysis of combining data from our study with the four previous studies(13-16), as infeasible given our study and another one study(13) used a weighted approach(19) while others did not(14-16).

A limitation of our study was the possibility that the estimates of association were only generalizable to MMR gene mutation carriers with substantial survival as, to be included in the analysis, cases had to survive long enough to provide a blood sample for DNA testing. Another limitation is that we had limited data on the type of colorectal polyps, which were removed, and therefore we censored at the age of polypectomy instead of estimating postpolypectomy CRC risk. This could have resulted in underestimating the true cancer risk if some of the polyps were malignant. Finally, the study was underpowered to detect weak associations of the SNPs with CRC risk. Assuming the risk allele frequency of each SNP to be $45 \%$ in unaffected carriers, our study of 927 MMR gene mutation carriers had $68 \%$ power to detect a $20 \%$ increased or decreased risk of CRC, and $23 \%$ power to detect a $10 \%$ increased or decreased risk of CRC, at the 0.05 level of significance.

Future studies should include a further four SNPs not included in this analysis that have been confirmed as being associated with CRC (1q41, 3q26.2, 12q13.13 and 20q13.33)(12). In addition, our study chose SNPs a priori based on previous associations with CRC in GWAS from the general population. It is unclear whether any of the millions of other SNPs tested, but not previously associated with CRC in the general population, may predict CRC risk for MMR gene mutation carriers.

In conclusion, our findings suggest that 11 SNPs identified from previous GWAS that were known to be associated with CRC risk in those general populations studied do not substantially alter the CRC risk of MMR gene mutation carriers. Therefore we found no evidence of proven clinical utility for these SNPs for Lynch syndrome carriers. The search for the hypothesized genetic modifiers of cancer risk due to MMR mutations should therefore examine other SNPs. Genome-wide association studies of Lynch syndrome colorectal cancer cases and controls is needed to identify these SNP modifiers, but given the rarity of the syndrome, international collaborations would be required to gain sufficient statistical power to adequately address this question.

\section{Supplementary Material}

Refer to Web version on PubMed Central for supplementary material.

\section{Acknowledgments}

The authors thank all study participants of the Colon Cancer Family Registry and staff for their contributions to this project. We thank Dr. Enes Makalic from the Centre for Molecular, Environmental, Genetic and Analytic Epidemiology, The University of Melbourne for his statistical advice.

Funding

This work was supported by the National Cancer Institute, National Institutes of Health under RFA \#CA-95-011 and through cooperative agreements with members of the Colon Cancer Family Registry and Principal Investigators. Collaborating centers include Australasian Colorectal Cancer Family Registry (U01 CA097735), Familial Colorectal Neoplasia Collaborative Group (U01 CA074799) [USC], Mayo Clinic Cooperative Family Registry for Colon Cancer Studies (U01 CA074800), Ontario Registry for Studies of Familial Colorectal Cancer (U01 CA074783), Seattle Colorectal Cancer Family Registry (U01 CA074794), and University of Hawaii Colorectal Cancer Family Registry (U01 CA074806). AKW is supported by the Picchi Brothers Foundation Cancer Council Victoria Cancer Research Scholarship, Australia. MAJ is an NHMRC Senior Research Fellow. JLH is an NHMRC Australia Fellow. JPY is a Cancer Council Queensland Senior Research Fellow. 


\section{Abbreviations}

$\begin{array}{ll}\text { CRC } & \text { colorectal cancer } \\ \text { Colon CFR } & \text { the Colon Cancer Family Registry } \\ \text { CI } & \text { confidence interval } \\ \text { HR } & \text { hazard ratio } \\ \text { MMR } & \text { mismatch repair } \\ \text { SD } & \text { standard deviation } \\ \text { SE } & \text { standard error } \\ \text { SNP } & \text { single nucleotide polymorphism }\end{array}$

\section{REFERENCES}

1. Ferlay, J.; Shin, H.; Bray, F.; Forman, D.; Mathers, C.; Parkin, D. GLOBOCAN 2008, Cancer Incidence and Mortality Worldwide. Lyon, France: International Agency for Research on Cancer; 2010.

2. Rustgi AK. The genetics of hereditary colon cancer. Genes Dev. 2007; 21(20):2525-2538. [PubMed: 17938238]

3. Hopper JL, Bishop DT, Easton DF. Population-based family studies in genetic epidemiology. Lancet. 2005; 366(9494):1397-1406. [PubMed: 16226618]

4. Limburg PJ, Harmsen WS, Chen HH, Gallinger S, Haile RW, Baron JA, et al. Prevalence of alterations in DNA mismatch repair genes in patients with young-onset colorectal cancer. Clin Gastroenterol Hepatol. 2011; 9(6):497-502. [PubMed: 21056691]

5. Burt RW, DiSario JA, Cannon-Albright L. Genetics of colon cancer: impact of inheritance on colon cancer risk. Annu Rev Med. 1995; 46:371-379. [PubMed: 7598472]

6. Baglietto L, Lindor NM, Dowty JG, White DM, Wagner A, Gomez Garcia EB, et al. Risks of Lynch Syndrome Cancers for MSH6 Mutation Carriers. J. Natl. Cancer Inst. 2010; 102(3):193-201. [PubMed: 20028993]

7. Senter L, Clendenning M, Sotamaa K, Hampel H, Green J, Potter JD, et al. The Clinical Phenotype of Lynch Syndrome Due to Germ-Line PMS2 Mutations. Gastroenterology. 2008; 135(2):419-428. [PubMed: 18602922]

8. Bonadona V, Bonaiti B, Olschwang S, Grandjouan S, Huiart L, Longy M, et al. Cancer risks associated with germline mutations in MLH1, MSH2, and MSH6 genes in Lynch syndrome. JAMA. 2011; 305(22):2304-2310. [PubMed: 21642682]

9. Dowty JG, Win AK, Buchanan DD, Lindor NM, Macrae FA, Clendenning M, et al. Cancer risks for MLH1 and MSH2 mutation carriers. Hum Mutat. 2012 [Epub ahead of print].

10. Tenesa A, Dunlop MG. New insights into the aetiology of colorectal cancer from genome-wide association studies. Nat Rev Genet. 2009; 10(6):353-358. [PubMed: 19434079]

11. von Holst S, Picelli S, Edler D, Lenander C, Dalén J, Hjern F, et al. Association studies on 11 published colorectal cancer risk loci. Br J Cancer. 2010; 103(4):575-580. [PubMed: 20648012]

12. Houlston RS, Cheadle J, Dobbins SE, Tenesa A, Jones AM, Howarth K, et al. Meta-analysis of three genome-wide association studies identifies susceptibility loci for colorectal cancer at 1q41, 3q26.2, 12q13.13 and 20q13.33. Nat Genet. 2010; 42(11):973-977. [PubMed: 20972440]

13. Wijnen JT, Brohet RM, van Eijk R, Jagmohan-Changur S, Middeldorp A, Tops CM, et al. Chromosome 8q23.3 and 11q23.1 variants modify colorectal cancer risk in Lynch syndrome. Gastroenterology. 2009; 136(1):131-137. [PubMed: 19010329]

14. Talseth-Palmer BA, Wijnen JT, Brenne IS, Jagmohan-Changur S, Barker D, Ashton KA, et al. Combined analysis of three Lynch syndrome cohorts confirms the modifying effects of $8 \mathrm{q} 23.3$ and 11q23.1 in MLH1 mutation carriers. Int J Cancer. 2012 [Epub ahead of print]. 
15. Talseth-Palmer BA, Brenne IS, Ashton KA, Evans TJ, McPhillips M, Groombridge C, et al. Colorectal cancer susceptibility loci on chromosome 8q23.3 and 11q23.1 as modifiers for disease expression in lynch syndrome. J Med Genet. 2011; 48(4):279-284. [PubMed: 21097774]

16. Houlle S, Charbonnier F, Houivet E, Tinat J, Buisine MP, Caron O, et al. Evaluation of Lynch syndrome modifier genes in 748 MMR mutation carriers. Eur J Hum Genet. 2011

17. Newcomb PA, Baron J, Cotterchio M, Gallinger S, Grove J, Haile R, et al. Colon Cancer Family Registry: an international resource for studies of the genetic epidemiology of colon cancer. Cancer Epidemiol Biomarkers Prev. 2007; 16(11):2331-2343. [PubMed: 17982118]

18. Win AK, Dowty JG, English DR, Campbell PT, Young JP, Winship I, et al. Body mass index in early adulthood and colorectal cancer risk for carriers and non-carriers of germline mutations in DNA mismatch repair genes. Br J Cancer. 2011; 105(1):162-169. [PubMed: 21559014]

19. Antoniou AC, Goldgar DE, Andrieu N, Chang-Claude J, Brohet R, Rookus MA, et al. A weighted cohort approach for analysing factors modifying disease risks in carriers of high-risk susceptibility genes. Genet Epidemiol. 2005; 29(1):1-11. [PubMed: 15880399]

20. Pande M, Lynch PM, Hopper JL, Jenkins MA, Gallinger S, Haile RW, et al. Smoking and Colorectal Cancer in Lynch Syndrome: Results from the Colon Cancer Family Registry and The University of Texas M.D. Anderson Cancer Center. Clin Cancer Res. 2010; 16(4):1331-1339. [PubMed: 20145170]

21. Grambsch PM, Therneau TM. Proportional hazards tests and diagnostics based on weighted residuals. Biometrika. 1994; 81(3):515-526.

22. Williams RL. A Note on Robust Variance Estimation for Cluster-Correlated Data. Biometrics. 2000; 56(2):645-646. [PubMed: 10877330]

23. Benjamini Y, Hochberg Y. Controlling the false discovery rate: a practical and powerful approach to multiple testing. Journal of the Royal Statistical Society. Series B (Methodological). 1995; 57(1):289-300.

24. Miller, RG. Simultaneous statistical inference. New York: Springer-Verlag; 1981.

25. Sokal, RR.; Rohlf, FJ. Biometry: the principles and practice of statistics in biological research. 3rd ed.. New York: WH Freeman; 1995.

26. StataCorp. Stata Statistical Software: Release 11. College Station, TX: StataCorp LP; 2009. In.

27. Dunlop MG, Tenesa A, Farrington SM, Ballereau S, Brewster DH, Kossler T, et al. Cumulative impact of common genetic variants and other risk factors on colorectal cancer risk in 42103 individuals. Gut. 2012 [Epub ahead of print].

28. Milne RL, Antoniou AC. Genetic modifiers of cancer risk for BRCA1 and BRCA2 mutation carriers. Ann Oncol. 2011; 22(Suppl 1):i11-i17. [PubMed: 21285145]

29. Bufill JA. Colorectal cancer: evidence for distinct genetic categories based on proximal or distal tumor location. Ann Intern Med. 1990; 113(10):779-788. [PubMed: 2240880]

30. Lindblom A. Different mechanisms in the tumorigenesis of proximal and distal colon cancers. Curr Opin Oncol. 2001; 13(1):63-69. [PubMed: 11148689]

31. Iacopetta B. Are there two sides to colorectal cancer? Int J Cancer. 2002; 101(5):403-408. [PubMed: 12216066]

32. Tomlinson IPM, Webb E, Carvajal-Carmona L, Broderick P, Howarth K, Pittman AM, et al. A genome-wide association study identifies colorectal cancer susceptibility loci on chromosomes 10p14 and 8q23.3. Nat Genet. 2008; 40(5):623-630. [PubMed: 18372905] 

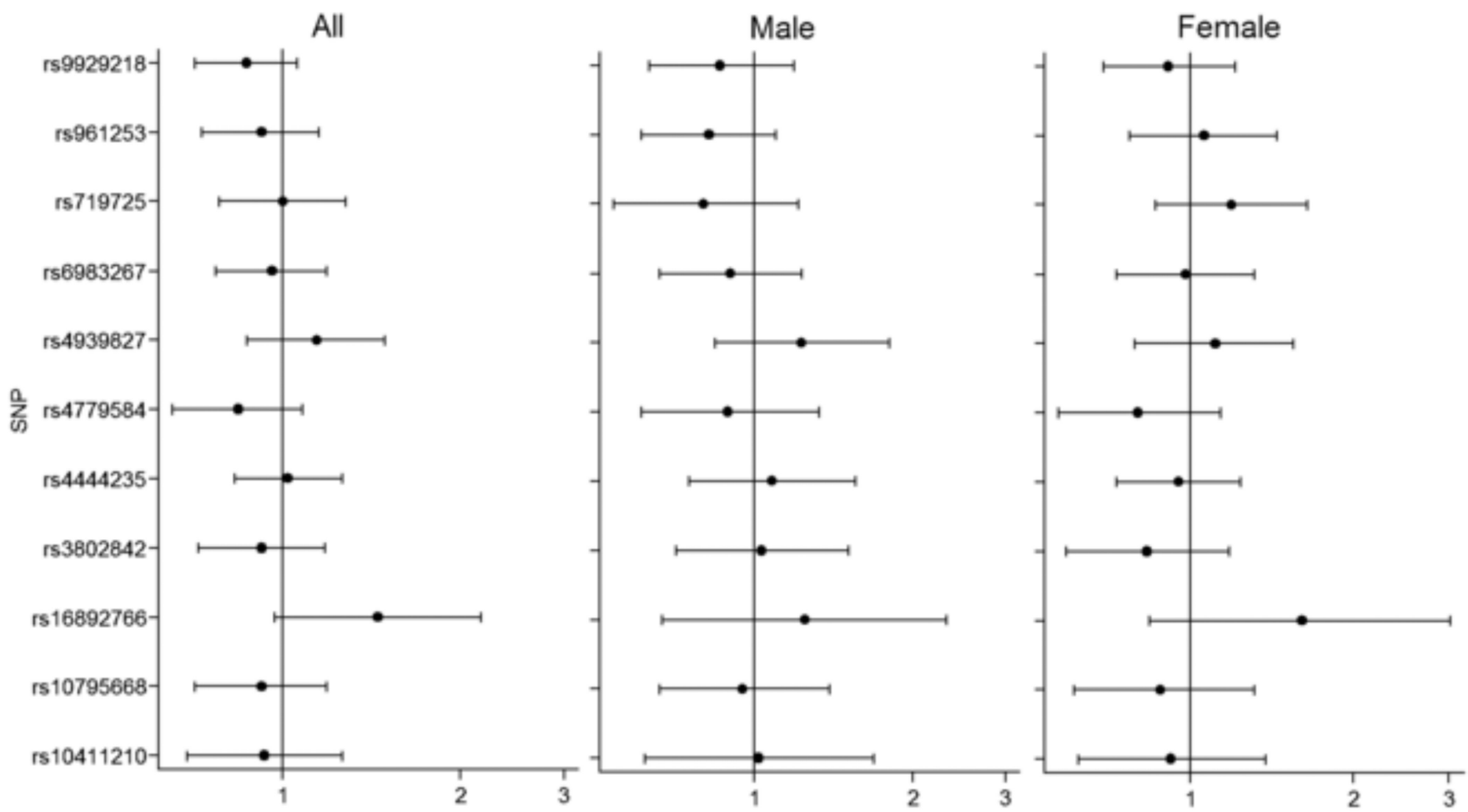

Figure 1.

Hazard ratios and $95 \%$ confidence intervals for associations between common genetic variants and colorectal cancer risk for mismatch repair gene mutation carriers. 

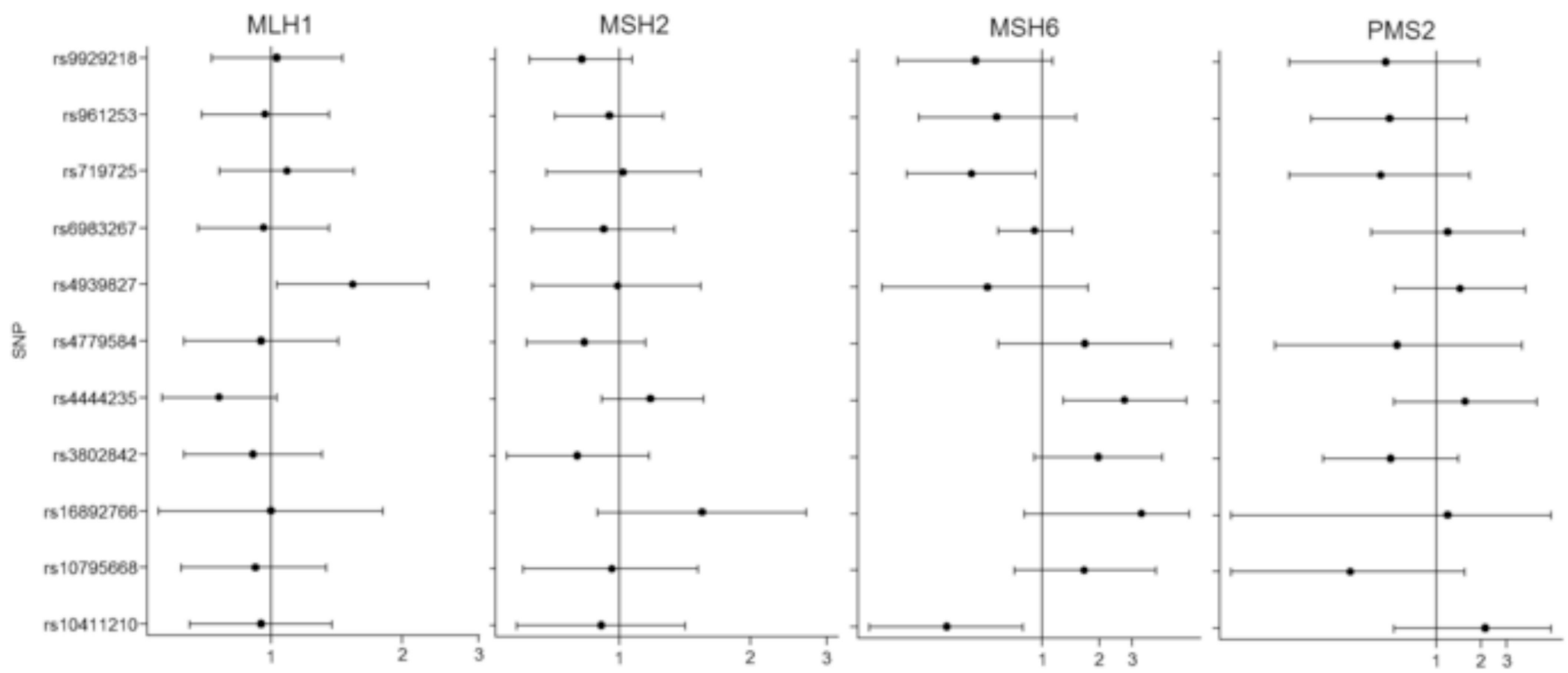

Figure 2.

Hazard ratios and $95 \%$ confidence intervals for associations between common genetic variants and colorectal cancer risk for carriers of mutations in specific mismatch repair gene. Note: Horizontal lines represent $95 \%$ confidence intervals. Each dot represents the point estimate for hazard ratio per allele. $\mathrm{X}$-axis as log scale. 
Table 1

Baseline characteristics of mismatch repair gene mutation carriers included in the study

\begin{tabular}{|c|c|c|c|}
\hline & $\begin{array}{r}\text { No colorectal cancer } \\
(\mathbf{n}=501) \\
\mathbf{N}(\%)\end{array}$ & $\begin{array}{r}\begin{array}{r}\text { Colorectal cancer } \\
(\mathrm{n}=\mathbf{4 2 6}) \\
\mathrm{N}(\%)\end{array}\end{array}$ & $\begin{array}{r}\text { All } \\
(\mathbf{n}=927) \\
\mathbf{N}(\%)\end{array}$ \\
\hline \multicolumn{4}{|l|}{ Sex } \\
\hline male & $204(41)$ & $204(48)$ & $408(44)$ \\
\hline female & $297(59)$ & $222(52)$ & $519(56)$ \\
\hline \multicolumn{4}{|l|}{ Country } \\
\hline Canada & $6(1)$ & $19(4)$ & $25(3)$ \\
\hline Australia or New Zealand & $429(86)$ & $309(73)$ & $738(80)$ \\
\hline USA & $66(13)$ & $98(23)$ & $164(17)$ \\
\hline \multicolumn{4}{|l|}{ Ascertainment } \\
\hline Population-based & $56(11)$ & $87(20)$ & $143(15)$ \\
\hline Clinic-based & $445(89)$ & $339(80)$ & $784(85)$ \\
\hline \multicolumn{4}{|l|}{ Gene mutated } \\
\hline$M L H 1$ & $180(36)$ & $180(42)$ & $360(39)$ \\
\hline MSH2 & $252(50)$ & $190(45)$ & $442(87)$ \\
\hline MSH6 & $53(11)$ & $32(8)$ & $85(9)$ \\
\hline PMS2 & $16(3)$ & $24(5)$ & $40(4)$ \\
\hline $\mathrm{Age}^{*} \quad$ Mean $(\mathrm{SD})$ & $44.15(14.17)$ & $44.26(11.05)$ & $4.20(12.82)$ \\
\hline
\end{tabular}

Age at diagnosis for carriers with colorectal cancer; age at diagnosis of other cancer or polypectomy or death or last contact for carriers without colorectal cancer. 
Table 2

Minor allele frequency of 11 SNPs included in the study

\begin{tabular}{|rrrr|}
\hline & $\begin{array}{r}\text { No colorectal } \\
\text { cancer }\end{array}$ & $\begin{array}{r}\text { Colorectal } \\
\text { cancer }\end{array}$ & All \\
\hline rs10411210 [T] & 0.12 & 0.13 & 0.12 \\
rs10795668 [A] & 0.30 & 0.30 & 0.30 \\
rs16892766 [C] & 0.06 & 0.08 & 0.07 \\
rs3802842 [C] & 0.28 & 0.29 & 0.29 \\
rs4444235 [C] & 0.47 & 0.48 & 0.48 \\
rs4779584 [T] & 0.23 & 0.22 & 0.22 \\
rs4939827 [T] & 0.46 & 0.48 & 0.49 \\
rs6983267 [T] & 0.45 & 0.48 & 0.47 \\
rs719725 [C] & 0.36 & 0.34 & 0.35 \\
rs961253 [A] & 0.38 & 0.36 & 0.37 \\
rs9929218 [A] & 0.29 & 0.30 & 0.29 \\
\hline
\end{tabular}




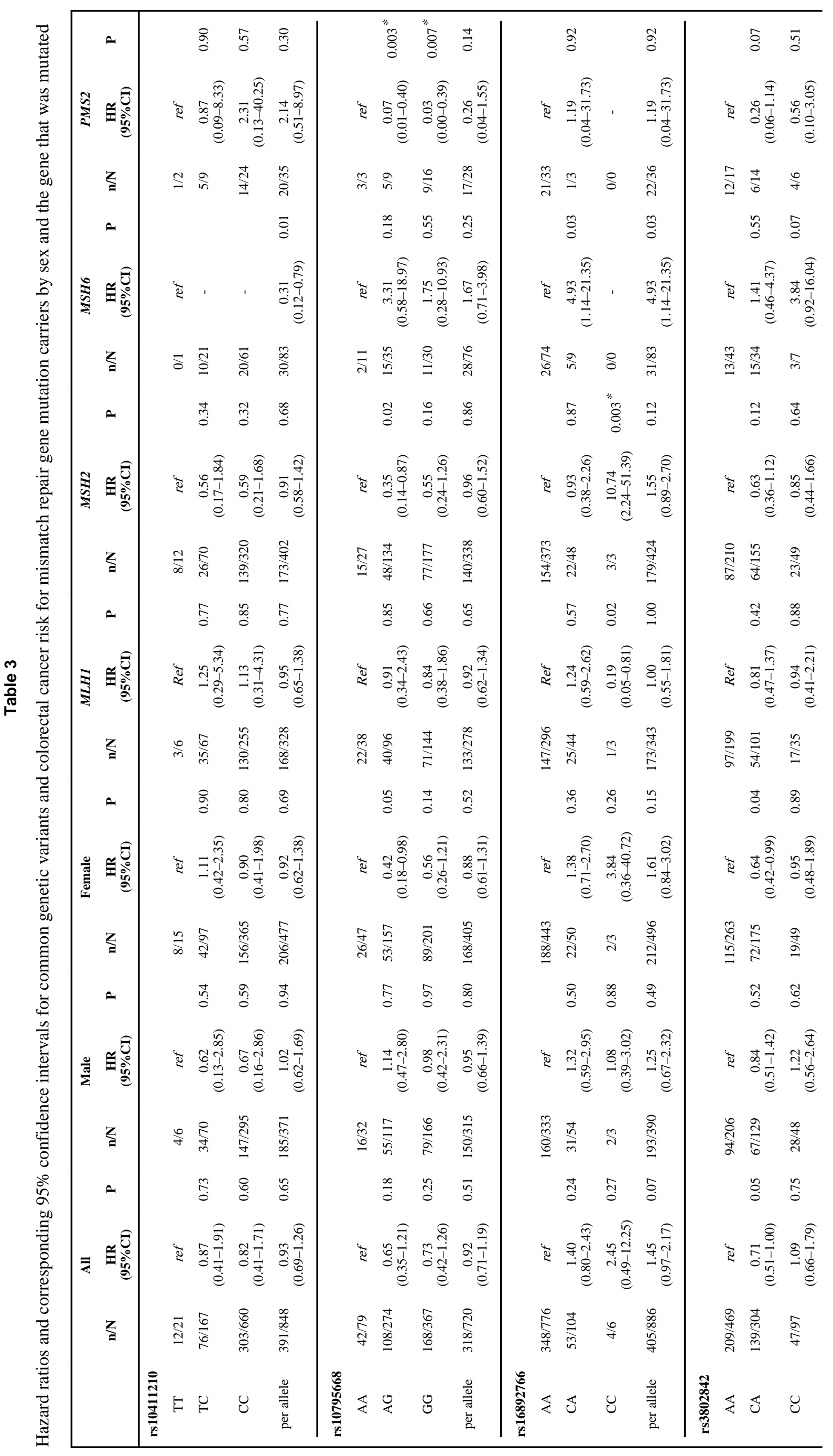




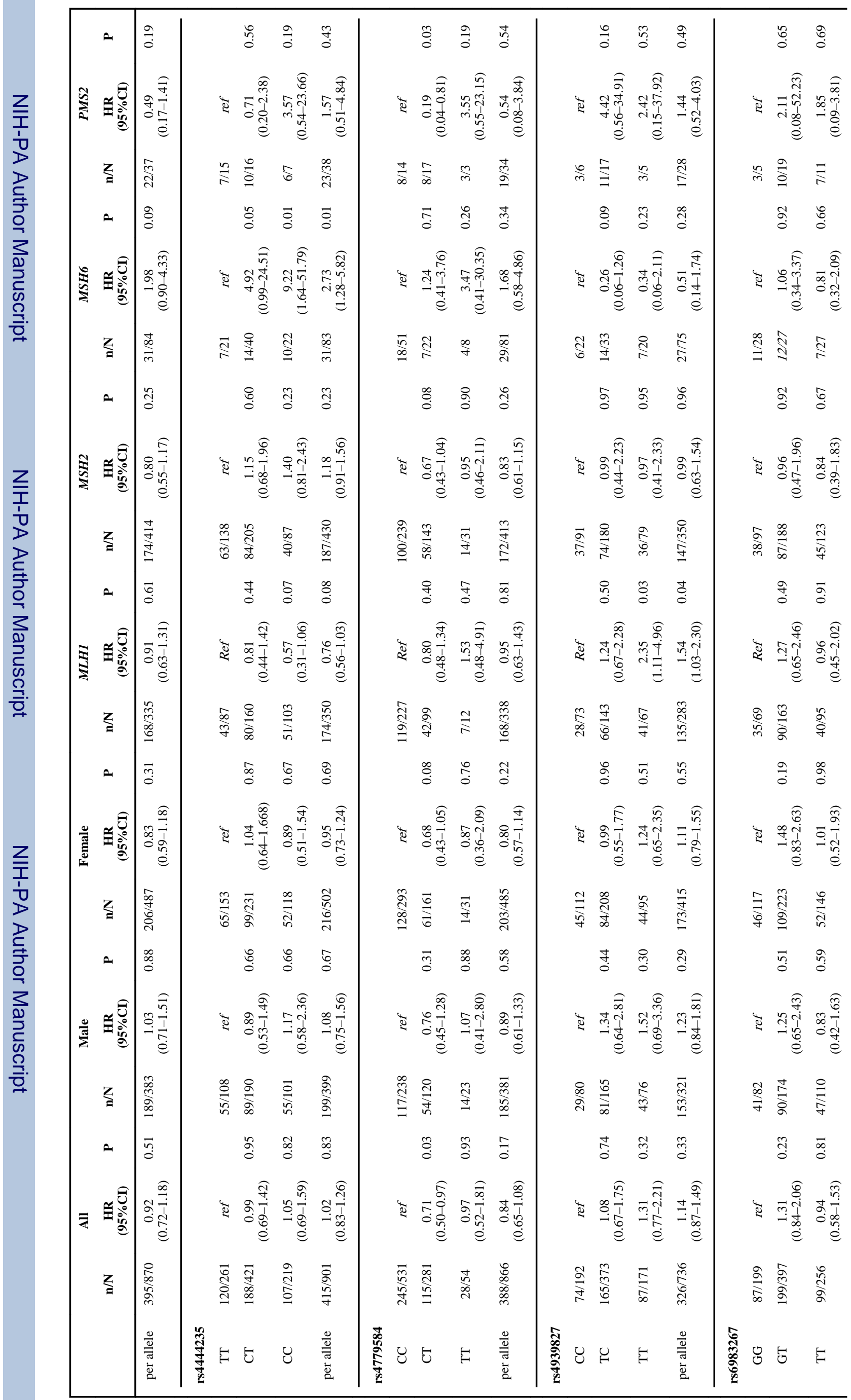




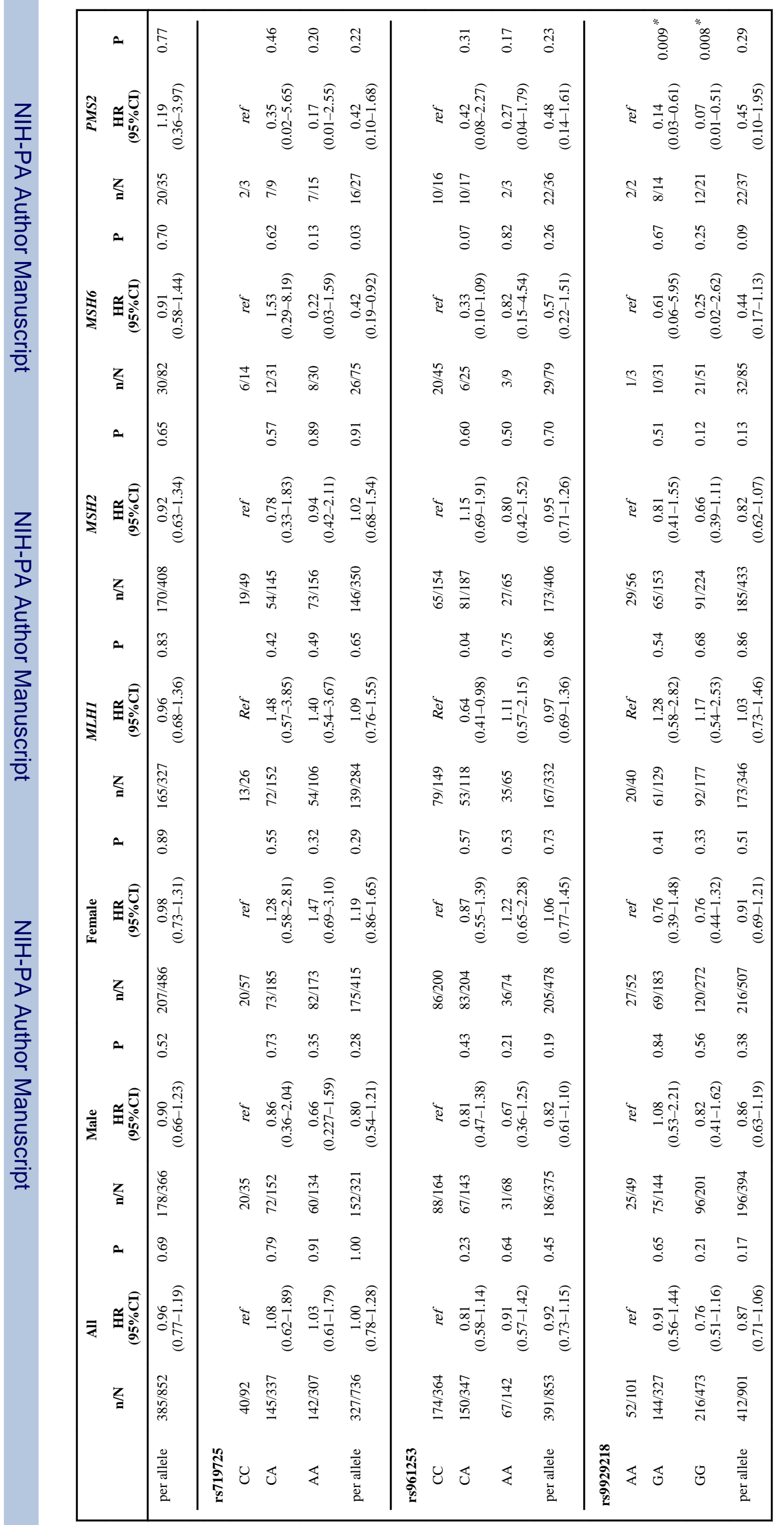

